\title{
CORRECTIONS
}

\section{A 71 year old man with right sided facial droop}

The online version of this Endgames picture quiz by Saad Saheecha and colleagues (BMJ 2011;343:d5121, doi:10.1136/ bmj.d5121) contained a mistake in the labelling of figure 2 . The explanations for labels $\mathrm{D}$ and $\mathrm{E}$ were published the wrong way round. D should have in fact indicated left ventricular aneurysm with thrombus [not the "descending aorta"] and E should have indicated the descending aorta [not "left ventricular aneurysm with thrombus"].

Cite this as: BMJ 2011;343:d6859

๑ BMJ Publishing Group Ltd 2011 